\title{
Tools as design instruments: computers and cognition?
}

\author{
Raid Hanna \\ Mackintosh School of Architecture, Glasgow, Scotland, UK \\ r.hanna@gsa.ac.uk
}

\begin{abstract}
This inquiry researches the impact of digital tools on the design process and empirically tests the association between computer aided design tools and each of cognition and creativity in architectural practice. The paper analyses the 'design-tool' relationship and reviews research in the field of computers as an instrument for creativity, examines their deductions and conducts a case study. Statistical analysis of the case study suggests that three measures of creativity correlated significantly with the length of time a subject spends using the computer in design: rho $=0.487, \mathrm{P}<0.05$ for elaboration of design ideas; rho $=0.605$, $\mathrm{P}<0.05$, for volume of ideas; rho=0.687, $\mathrm{P}<0.05$, for ideation variety. Also, the length of designer-computer interaction seems to scaffold various forms of design reasoning and help cognition: $r h o=0.591, \mathrm{P}<0.05$. The study found little evidence to support the notion that computers prevent other forms of knowing.
\end{abstract}

Keywords: cognition, computers, tools, creativity

\section{The cognition of Design-tool Relationship}

Tools and their impact on design conception have a long history in architecture. Such tools include sketches, physical models and computer models, sometimes viewed as representation techniques, are used by architects to explore different aspects of a design idea with each being advocated as being the most appropriate for a particular stage of the design process.[1] Representations may also guide the orientation of thoughts and acquire the function of an indirect instrument of enablement, which implies that 'the choice of representation can influence the discussion focus'.[1]

Schweikardt and Gross [2] suggest that sketching at the early design stages followed by computer aided design (CAD) models are useful means to explore design ideas and aid cognition. They cite Michael Graves, who states that: 'the tension of lines on paper or cardboard in space has an insistence of its own that describes possibilities which perhaps could not be imagined in thought alone. 'Furthermore, Heath [3] suggests that the nature and power of tools at the disposal of a designer and their ability to muster them can seriously affect their capacity to conceive design ideas and generate solutions. He avers, the confines of method inhibit thinking and will be revealed as limitations of the design. So if a student cannot sketch freely, her/his designs will be affected by this limitation in representation. If one accepts that design 
tools such as computers are entities that are external to the mind, then designers interact with these tools creating 'a coupled system that can be seen as a cognitive in its own right.'[4] Tools are sometimes described as languages or design methods can aid architectural discernment. For example, on examining the value of languages such as words, drawings and models as a vehicle for architectural thought, the conclusions suggest that 'more differentiated environmental forms are the result of more differentiated thought processes and these require differentiated architectural languages'.[5]

Today's tools in design are computers and some of the complexity of the design process can only be resolved effectively with the use of the computer in the modelling as well as manufacturing process. Novak [6] argues that 'the most advanced and challenging architecture being designed around the world could not have been conceived without the use of the computer.'[6]

Dewey [7] states 'all art is instrumental in its use of techniques and tools' and suggests that the activity of problem solving is a search to find the optimum tool. The tool's perception, 'as well as its actual use takes the mind to other things.' Furthermore, Dewey [7] avers that it is not the fulfilment of tasks or the functional aspect that is the real concern of technology, but the connection to external things or 'the sequential bond in nature'. He states, 'technology is concerned with things and acts in their instrumentalities, not in their immediacies'.[7]

Likewise, Janney [8] argues that computers can be considered as 'prosthetic tools' which can enhance the potential and the capabilities of the human mind but also warns that the 'enthusiasm for computers as potential extensions of the mind should not blind us to the fact that all extensions of human faculties have their price'. Similarly, Friesen [9] suggested a 'metaphorical connection' between technology and the 'conception of the mind' and that devices like the computer can be a very useful and powerful means for understanding the mind.

Jonassen and Strobel [10] examined mental models and computer modelling, suggesting that building computational models of the world using modeling tools can help to 'externalize learners' mental models of the phenomena that they are studying.' Further, Jonassen [11] claims that despite recent significant progresses on the technology of media and information, our understanding of its impact on 'our ways of knowing is not well developed'. He identified four dimensions on how technology can mediate our experience. These are: intellectual; perceptual; simulation of reality; epistemological and ontological. Furthermore, Jonassen, Carr and Yueh [12] use the term 'mind-tools' to refer to computer software, or applications. They maintain that 'mind-tools', when used to represent the user's state of knowing can, help different forms of reasoning in problem solving Additionally, computer tools can serve as intellectual partners to aid performance. According to Salomon, Perkins and Globerson:

'The performance of such a partnership between a human and technology could be far more intelligent than the performance of the human alone. Moreover, effects of technology can occur when partnership with a technology leaves a cognitive residue, equipping people with thinking skills and strategies that reorganize and enhance their performance even away from the technology in question. '[13] 
Jonassen and Cho [14] examined the notion of using computer based mind tools to generate an external representation of 'mental models' and suggested 'externalizing mental models improves the utility, coherence, and cogency of mental models'. Similarly, Johnson-Laird [15] stated, 'To understand a phenomenon is to have a working model of it, albeit a model that may contain simulated components'. Spector and Kinshuk [16] assert that technology can serve two important functions. When used as a tool it can progress 'expertise' in problem solving and improve decision making during problem identification and selection. Secondly, as a generative tool in problem solving, they maintain that it is well known that technology can be used to suggest realistic 'problem solving scenarios and interactive simulations'.

Furthermore, Moore [17] opined, tools are 'extensions of ourselves' and 'they are both mental and physical prosthesis that can significantly enhance our capabilities. Similarly, Rosenberger [18] examined technology as a mediator of experience. He asserts that technology changes our relationship with the world as it can enable new experiences enhancing certain dimensions of our perception, but at the same time it will also act as a disabler which 'cuts off the potential for others'. However, this important statement has not been empirically tested

Heidegger defines the 'essence' of technology in terms of: means to an end, a human activity and as an 'instrument'. He suggests wherever 'instrumentality reigns, there reigns causality'.[19] Furthermore, he identifies causality as being: material, form, subjective will of maker, and functional. He concludes: 'technology is therefore no mere means... technology is a way of revealing' as well as 'the possibility of all productive manufacturing lies in revealing'.[19]

More specifically to architecture, Posngratz and Perbellini [20] affirm that the architecture produced by some practices through computers, is different both in outcome and process; it is a type of innovative architecture which entertains a high level of complexity in design; that delves into geometries which were previously impossible to pursue. Similarly, Rahim [21] maintains what distinguishes innovative CAD practices is their departure from traditional design philosophies and processes. He asserts that contemporary processes rely on modes of thought that are 'nondeterministic' and 'non-static'.

In summary, it seems that most of the surveyed literature on tools as extension of cognition in problem solving remains largely theoretical in nature and lacks empirical support through evidence from case studies.

\section{Creativity, its Measurement and Computer Tools}

Creativity is the ability to produce work that is novel, original, unexpected and appropriate, i.e. useful and adaptive to constraints. A number of tests have been devised and validated for measuring creativity, by assessing either verbal ability through remote association, or visual ability and/or unusual uses tests. One of the most common ones is RAT (remote association test), where the subject is usually given three unrelated words and is required to find a fourth word which can link the three words.[22] However the suitability of this method for some professions was questioned, especial- 
ly when 'the production of remote verbal associations is not as important a component of behavioural creativity for professional engineers as it maybe for psychology and design.'[23]

Torrance [24] identified four main parameters for creativity: fluency (generating a volume of ideas); flexibility (the variety of ideas); originality (uncommonness of ideas); elaboration (advancing an idea). Runco and Chand [25] developed a two-tier creativity model. The primary tier has three components: problem finding, ideation (fluency, flexibility, originality), and evaluation. The secondary tier has two components: knowledge (declarative and procedural) and motivation. Two additional modes of thinking, convergent (a single path solution) and divergent (multi path solution), were widely reported in the literature to impact creativity in problem solving.

The bulk of research seems to focus on creativity as a process of thinking. In comparison, research on the creativity of 'products', is less in quantity. Amabile [26] attempted to develop a 'consensual' definition of creative product which aimed to establish a reliability assessment from a group of judges on the creativity of products. Amabile's assessment tool for creative products had three dimensions: creativity judgement, technical judgement and aesthetic judgement. However, the idea and of using appropriate judges to assess a product was pioneered by Mackinnon [27], who wanted to examine the traits of personality associated with creativity in architecture, and to that end he independently asked five American professors of architecture to nominate who they believed to be the forty most creative architects from the USA. According to Mackinnon, it was important to reach an agreement between the five experts on 'who are the more and who are the less creative workers in a given field of endeavour'.

Some variables related to architectural creativity were examined in seventeen graduating architectural students who were rated in terms of creativity by two professors familiar with their work, and the scores were correlated with a battery of creativity tests.[28] Architectural creativity was not found to correlate with 'measures of academic aptitude' such as class rank and grades, but correlated with the 'quality of their design projects and their performance on the spatial factor test'. The spatial factor involves two parameters: spatial orientation and visualisation. Following from this, one could argue that using computer tools in design is bound to affect both parameters and consequently it may influence architectural creativity.

The impact of computer based tools on decision support systems (DSS) which could enable problem solvers to develop more creative solutions was examined experimentally by Elam and Mead [29] using a three-group design. With regards to creativity enhancing-DSS, the study found that computers do influence the decision-making processes of their users and these systems affect the creativity of decisions. However, the study also noted that the software can 'undermine creativity as well as enhance it' and calls for understanding the manners in which the software affects both creativity and the decision making process.

Candy [30] examined the relationship between creative support systems such as computers, models of cognition and qualities of creative work and concluded that to support the needs of the creative user, the support system has to provide and facilitate 
three functions: knowledge appraisal and addition, visualisation, and collaboration between teams.

The thoughts of architecture students toward the design process were measured in the studio at two points in time: before and after using the computer.[31] Analysis of measurements revealed a significant difference in attitudes toward design variables when subjects were asked to use CAD in design and the use of CAD was found to produce a positive influence on the creative process as CAD seems to facilitate the $3 \mathrm{D}$ visualisation and testing of design concepts, increase ideation fluency and help the conception of complex geometry.

In summary, although research on measures of creativity had focused on problem solving, it did not directly relate to design in architecture. Also very few studies were reported in the literature to deal with the impact of computers on design creativity in architecture. After searching the database of both ACADIA and ECAADE conference proceeding, few papers were found that 'empirically' dealt with the relation between creativity and parametric design.[32] Using a small sample of 3 subjects only the paper concluded that the 'space of possible design solutions was expanded with the existence of unexpected outcomes' offered by parametric tools. Moreover, the paper does not provided any operational definition for creativity although one would assume that divergent thinking was used as a measure for creativity. Another paper by Asanowicz [33] investigated the potential of using computer software to creatively 'search' for design ideas. He concluded that computers can serve as a useful interface. Or what he calls 'the arbitrator between the designer and ideas'.

\section{Case Study}

In order to test some of the aforementioned variables in the previous sections, the research conducted a case study. Questionnaires were administered to architectural practices which used CAD regularly in their design schemes. The number of years spent by a subject (architect) on using CAD for design work was taken as a measure of computing experience. Initially 45 practices signed up to take part but returns were only received from 32 subjects. The questionnaire dealt with two groups of variables. The first, included 4 variables each representing a single parameter of creativity adopted from Torrance [24] that might be affected by the use of CAD. The second consisted of several variables each concerning a single issue of design cognition which could be influenced by the use of CAD. Returns were analysed using the Statistical Package for Social Sciences (IBM_SPSS 20). Levels of statistical significance of $<0.05$ between any 2 variables were taken to mean that the association between the variables is causal; it has a $95 \%$ certainty and only a $5 \%$ probability of it being the result of a statistical chance.[34]

The main aim of the statistical analysis is to 'correlate' time, i.e. years of experience in using CAD, with attitudes toward 'creativity' and 'design cognition.' The logic behind the correlation is based upon the postulate that computer enhanced creativity is time dependent; the more time a subject spends on the tool (the computer) the more fluent they become in using the tool and getting the most out of its ideation 
potential. In the same way, computer mediated cognition is assumed to be time dependent, as more time means more cognitive exposure to $\mathrm{CAD}$, which, in turn, may or may not lead to a more efficient design process. The findings on creativity parameters are summarised in Table 1, which describes the correlation between years of experience and each of the 4 parameters of creativity.

Table 1. Correlation coefficient between years of CAD experience and creativity parameters

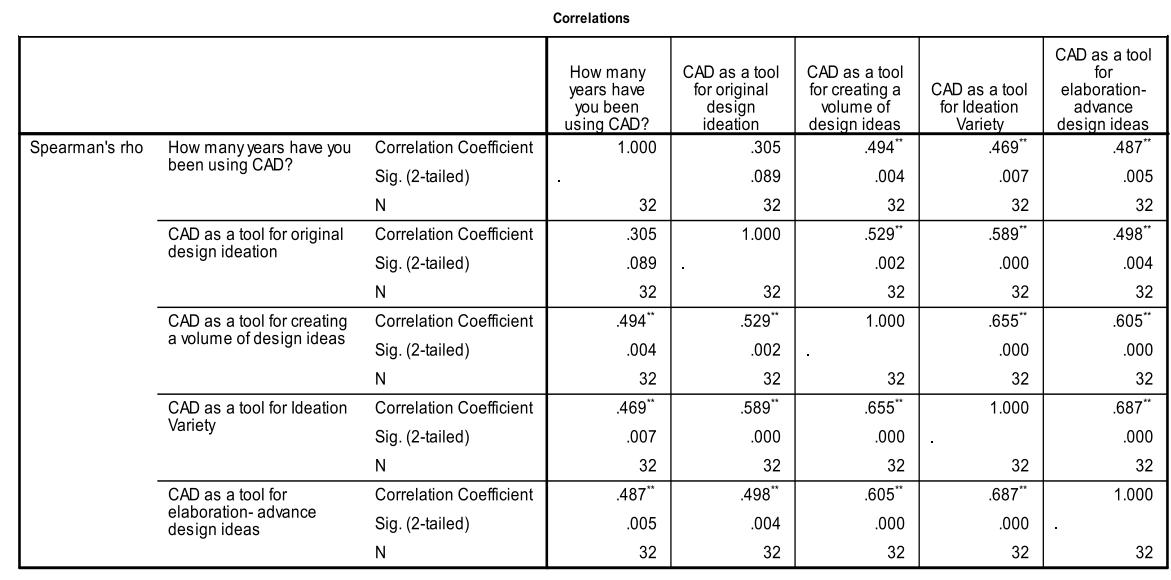

**. Correlation is significant at the 0.01 level (2-tailed).

Table 1 confirms that years of exposure to CAD has correlated significantly: with $\mathrm{CAD}$ as a tool creating a volume of design ideas (0.494); CAD as a tool for generating a variety between ideas (0.469); CAD as a tool for advancing design ideas (0.487). However, the correlation with originality was not significant. This implies that years of exposure to CAD as an 'independent variable' has influenced subjects' attitudes toward 3 parameters of creativity as 'dependent variables'. Yet CAD was not seen as a useful tool for creating original design thoughts. Some returns seem to suggest that the power of CAD as a tool lies in its potential for the editing, manipulation and translation of objects from 2D to 3D. Once a design idea is conceived, it becomes like a seed which can then be multiplied, mirrored or deformed to create a 'variety' of ideas. The advancement of an idea (elaboration) also seems well supported by CAD tools. Entities in CAD software have vertices that can be stretched or manipulated, causing a change in shape or geometry, according to one subject. Modifiers can also be applied to 3D geometry to change and progress it further. Sometimes the visual feedback given by CAD software in terms of light simulation, may help the designer to improve the design scheme, said another subject.

Although years of experience did not correlate with originality, it did however show a significant correlation with the other three parameters of creativity in terms of ideation: fluency, variety and elaboration. This implies that in subjects' mind the four parameters appear to be perceptually linked together. This also indicates a close association between creativity parameters and a higher internal 'validity' for the four creativity measures. On ideation fluency, i.e. CAD as a tool for generating a volume of 
ideas, results indicate that 16 architects reported that CAD had helped them to generate an average of more than 4 design ideas per scheme. Figure 1 breaks down the numbers into categories based on years of experience in using CAD. The absence of any negative correlation between years of experience in CAD and originality also indicates that subjects with a lesser experience in using CAD did not score high on originality.

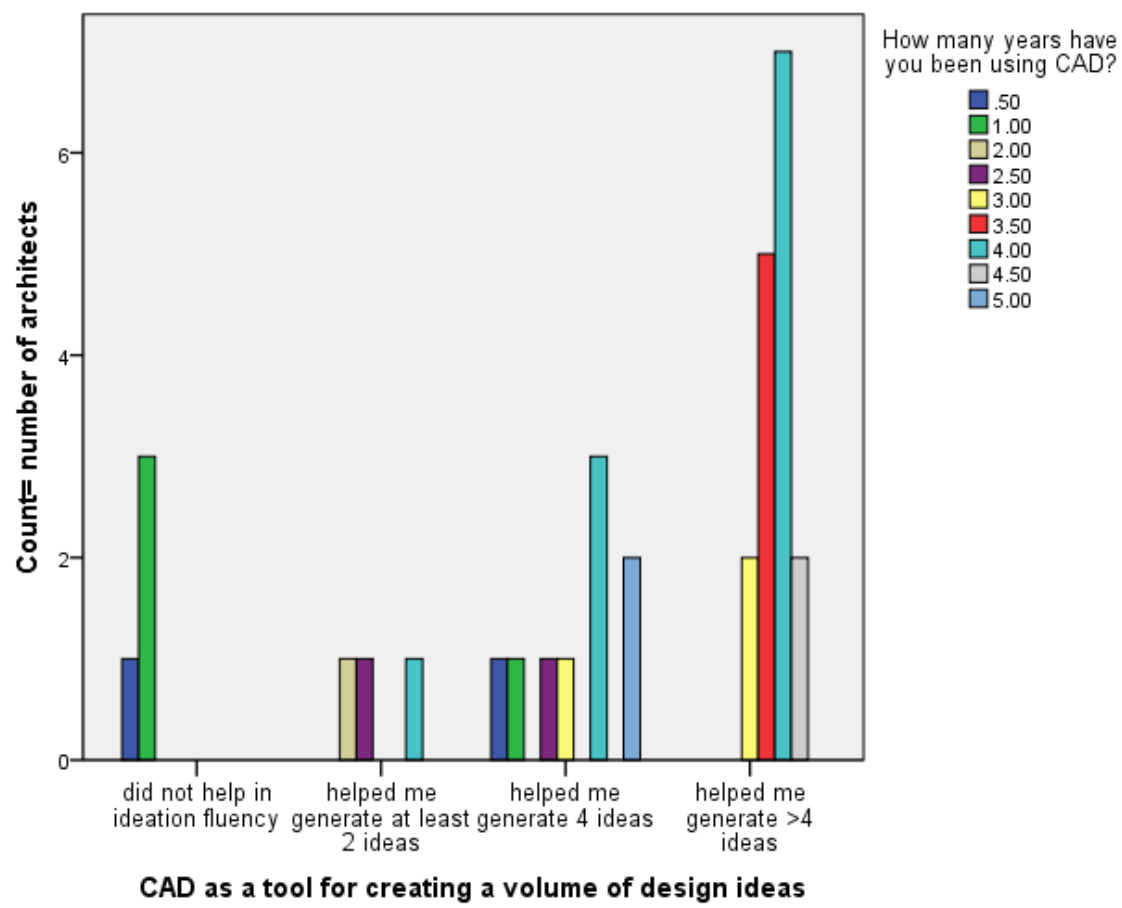

Figure 1. Number of architects in each experience category (Y-axis) against volume of design ideas (X-axis)

It is obvious that subjects' increased experience in using CAD (3.5-5 years) has enabled them to produce at least 4 different ideas for each design scheme. There could be factors like age and length of time in practice that could have also contributed to this association. It seems plausible to suggest that both design maturity and problem solving skills improve with experience. The findings on design cognition and the impact of CAD on designers' mind are presented in Table 2. Design cognition is defined as the process of receiving and processing design information. The length of exposure to $\mathrm{CAD}$ as a variable, correlated significantly with the variable 'tools extend the mind', the assumption being that $\mathrm{CAD}$ tools generally help the mind by reducing the cognitive load and/or by improving the efficiency of information processing in design. The correlation coefficient calculated was 0.591 , with significance $<0.05$. 
Table 2. Association between years of exposure to CAD and design cognition

\begin{tabular}{|lll|r|r|}
\hline \multicolumn{3}{|l}{ Correlations } \\
\hline
\end{tabular}

${ }^{* *}$. Correlation is significant at the 0.01 level (2-tailed).

CAD tools can help cognition in many ways. Some returns suggest that tools provide a powerful platform for $3 \mathrm{D}$ visualisation and representation, an easy means for object translation from $2 \mathrm{D}$ to $3 \mathrm{D}$ and are an optimum medium for conceiving and representing complex geometry. Organic and curvy geometry is difficult to represent and draw accurately in $3 \mathrm{D}$ without $\mathrm{CAD}$ tools. This type of geometry while in planar format, i.e. two dimensional (2D) is easy to conceive and draw, but when it is in a 3D format, it becomes more difficult to imagine accurately and draw precisely as the level of complexity increases significantly. CAD tools can accurately represent complex geometry through a quick generation of perspectives which offer the designer a vehicle for the visual testing. Also, by accurately representing this type of geometry externally, the cognitive load on the designer's mind could be reduced, one response reads. The research wanted to examine if the mental capacity required for dealing with complex geometry would be affected without CAD tools and if this is associated with the notion that CAD tools can extend design cognition. Table 3 displays a very high correlation coefficient $(0.825)$ between the two variables. This infers that 'design cognition' and 'complexity' are very closely perceived in subjects' minds and if CAD tools are seen to extend one then by implication it will improve the other.

Table 3. Association between CAD extending design cognition and CAD extending mental capacity for handling complexity

Correlations

\begin{tabular}{|c|c|c|c|c|}
\hline & & & $\begin{array}{l}\text { Mentally-do } \\
\text { you feel that } \\
\text { CAD tools } \\
\text { have } \\
\text { helped/extend } \\
\text { ed your } \\
\text { design } \\
\text { cognition? }\end{array}$ & $\begin{array}{l}\text { Without CAD, } \\
\text { do you feel } \\
\text { that your } \\
\text { mental } \\
\text { capacity in } \\
\text { dealing with } \\
\text { complex } \\
\text { geometry will } \\
\text { be affected? }\end{array}$ \\
\hline \multirow[t]{2}{*}{ Spearman's rho } & $\begin{array}{l}\text { Mentally-do you feel that } \\
\text { CAD tools have } \\
\text { helped/extended your } \\
\text { design cognition? }\end{array}$ & $\begin{array}{l}\text { Correlation Coefficient } \\
\text { Sig. (2-tailed) } \\
\mathrm{N}\end{array}$ & $\begin{array}{r}1.000 \\
32\end{array}$ & $\begin{array}{r}.825^{\text {*t }} \\
.000 \\
32\end{array}$ \\
\hline & $\begin{array}{l}\text { Without CAD, do you feel } \\
\text { that your mental capacity } \\
\text { in dealing with complex } \\
\text { geometry will be affected? }\end{array}$ & $\begin{array}{l}\text { Correlation Coefficient } \\
\text { Sig. (2-tailed) } \\
\mathrm{N}\end{array}$ & $\begin{array}{r}.825^{\star *} \\
.000 \\
32\end{array}$ & $\begin{array}{r}1.000 \\
32\end{array}$ \\
\hline
\end{tabular}

**. Correlation is significant at the 0.01 level (2-tailed). 
On the question of CAD scaffolding other forms of design reasoning in relation to years of CAD usage, the results are displayed in Figure 2.

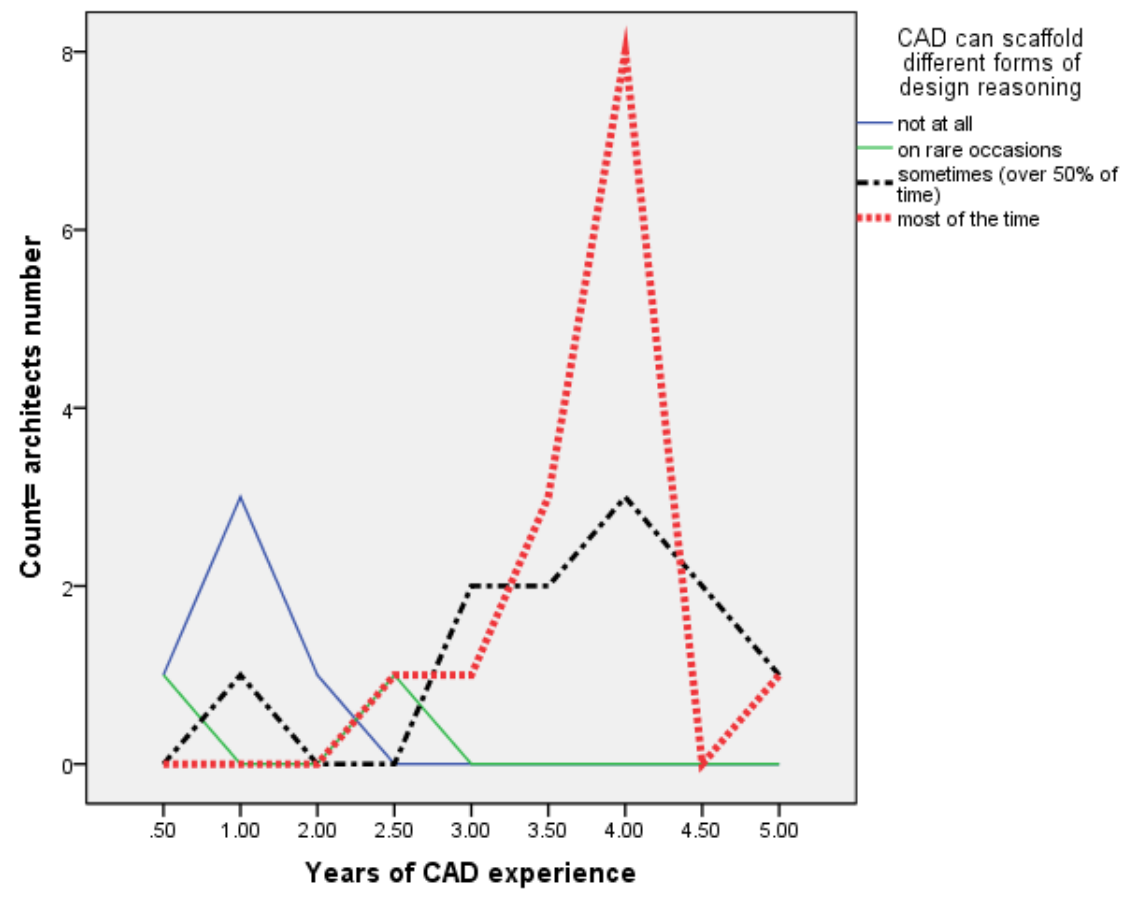

Figure 2. Years of experience in CAD against CAD scaffolding other forms of design reasoning

Figure 2 indicates that 11 subjects who had 3.5-4 years of experience in CAD intimated that $\mathrm{CAD}$ can scaffold different forms of reasoning most of the time while 7 subjects between 3-4 years of experience suggested that CAD can scaffold design reasoning over $50 \%$ of the time. Results from this case study suggest that CAD tools to have 'a momentum of their own'- median of 3 out of 4, Figure 3 - and interacting with such tools does impact design cognition and can scaffold design reasoning during problem solving. The length of interaction or exposure to CAD tools seems to play a significant role in this 'creative' mind-tool relationship. Interestingly Figure 3 also shows that CAD did not deny the subjects other forms of knowing (median of 1 out of 4). However, these results seem to be in contrast with the message conveyed by the famous architect Michael Graves [35] when he warns against architecture being in favor of technology and divorcing itself from drawing. He poses some questions: 'Are our hands becoming obsolete as creative tools? Are they being replaced by machines? And where does that leave the architectural creative process?'[35] 


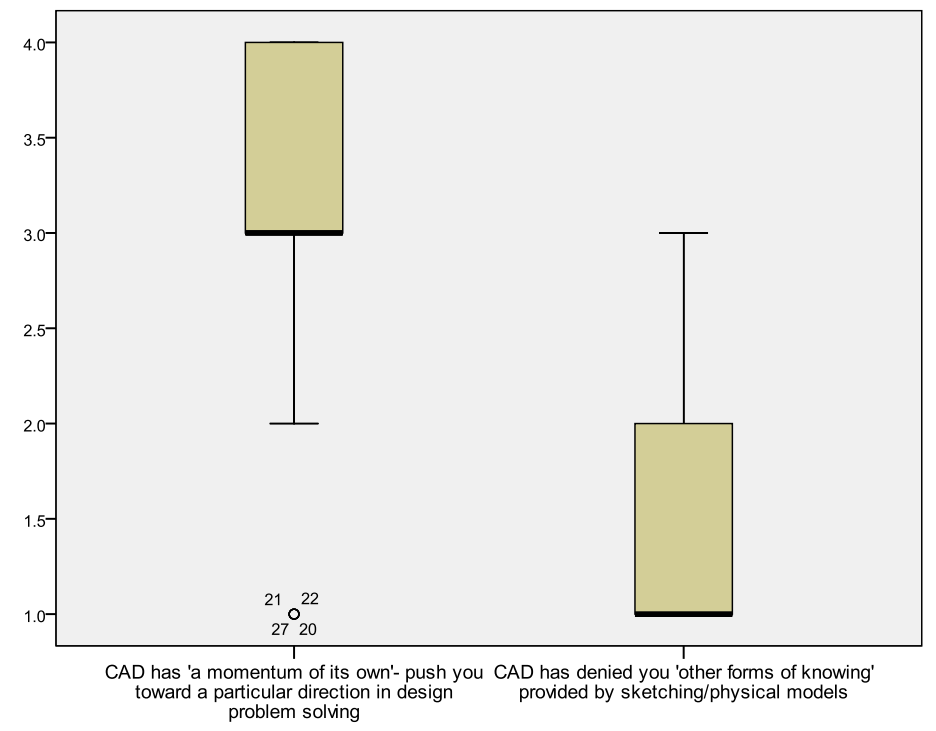

Figure 3. Boxplot showing the median statistics

\section{Conclusions}

This paper was conceived to address TWO gaps in knowledge with regards to $\mathrm{CAD}$, creativity and cognition. On creativity, most of the literature falls within the disciplines of psychology and education with very little that deals with creativity in architectural design. On the issue of creativity and CAD there is an even less established knowledge that is empirical in nature. On cognition, again the literature on tools as an extension of the mind is theoretical in nature and needs to be adapted to make it relevant to design in architecture. The research approach in this paper tackles both problems and makes a contribution to knowledge on design computing in architecture.

However, any conclusions drawn here have to be viewed with care due to the small sample size, although the survey sample of 32 was just above the critical size of 30 , required for statistical analysis. However, the use of statistics adds rigor to the study and strengthens the research methodology.

The main findings from this study confirm that years of experience in using CAD tools correlate positively with three of the four dimensions of creativity. CAD tools appear to be helpful with advancing design ideas and generating both a volume and variety of ideas by manipulating geometrical entities. The tools were unable to create original solutions to design problems. One of the weaknesses of these tools is that they are not knowledge- based systems, meaning that they can deconstruct a design concept and test it. For example CAD software including performance-analysis tools can inform the designer about the performance of a specific type of geometry, but cannot suggest a new geometry. Equally, years of exposure to CAD proved to be 
instrumental in scaffolding various forms of design reasoning. Skill and proficiency in the use of tools can help design cognition and may also extend the design mind and make it more adept in dealing with issues such as complex geometry. The findings also confirm that four variables of design cognition affected by CAD tools, namely: 'mental capacity', 'problem solving skills', 'tools have a momentum of their own' and 'tools being detrimental to other forms of knowing', seem to have a hierarchical link in perception. When subjects were asked to rate the 4 variables in the order they first appear in their perception the response was as follows: CAD and design problem solving skills, then CAD tools being detrimental to other forms of design knowing, followed by CAD tools have a momentum of their own- pushes you towards certain design concepts, and ending with CAD tools' impact on mental capacity.

\section{References}

26. Amabile, T.: Social psychology of creativity: a consensual assessment technique, Journal of Personality and Social Psychology, 43, 997-1013 (1982)

33. Asanowics, A.: How to find ideas? Computer-aided creativity, in Architecture in Computro, $26^{\text {th }}$ eCAADe conference, Antwerp, Belgium (2008)

34. Bryman, A. and Cramer, D.: Quantitative data analysis for social scientists, Routledge, London, 189 (1994)

30. Candy, L.: Computer and creativity support, Knowledge Based Systems, 10, 313 (1997)

32. Chien, S. F. and Yeh, Y. T.: On creativity and parametric design, in Digital Physicality, $30^{\text {th }}$ eCAADe conference, Czech Technical University, Prague (2012)

4. Clark, A. and Chalmers, D.: The extended mind, Analysis, 58, 7-19 (1998)

23. Datta, L. E.: Remote associates test as a predictor of creativity in engineers, Journal of Applied Psychology, 48, 183 (1964)

7. Dewey, J.: Experience and nature, Courier Dover Publications, New York, viii$123(1958)$

29. Elam, J. and Mead, M.: Can software influence creativity? Information Systems Research, 1, 1-23 (1990)

9. Friesen, N.: Mind and machine: ethical and epistemological implications for research, AI and Society, 25, 83-92 (2010)

35. Graves, M.: Architecture and the lost art of drawing, New York Times, 2.9.(2012)

31. Hanna, R. and Barber, T.: An inquiry into computers in design: attitudes before-attitudes after, Design Studies, 22, 255-281(2001)

Heath, T.: 1984, Method in architecture, John Wiley and Sons, London, Chapter 1.

19. Heidegger, M.: The question concerning technology, in D. Krell (ed.), Martin Heidegger: Basic Writings, Harper Collins, San Francisco, 321 (1993)

1. Hornecker, E.: Sketches, drawings, diagrams, physical models, prototypes, and gesture as representational forms, paper presented in Physicality 2007, The Second International Physicality Workshop, University of Lancaster, UK (2007)

5. Janke, R.: Architectural models, Academy Editions, London (1978) 
8. Janney, R.: Computers and psychosis, in human interfaces questions of method and practice in J. Marsh, B. Gorayska and J. Mey (eds.), Cognitive technology, Elsevier, Amsterdam, 71-79 (1999)

15. Johnson-Laird, P.: Mental models: Toward a Cognitive Science of Language, Inference and Consciousness, Harvard University Press, Cambridge, 4 (1983)

11. Jonassen, D.: The mediation of experience, Educational Technology and Communication Journal (ECTJ), 32, 153-167 (1984)

12. Jonassen, D., Carr, C. and Yueh, H.: Computers as mind tools for engaging learners in critical thinking, Tech Trends, 43, 24-32 (1998)

14. Jonassen, D. and Cho, Y. H.: Externalizing mental models with mindtools, in D. Ifenthaler, P. P. Dummer and M. Spector (eds.), Understanding Models for Learning and Instructions, Springer Science + Business Media LLC, New York, 145-159 (2008)

10. Jonassen, D. and Strobel, J.: Modelling for meaningful learning, in D. Hung and M. Khine (eds.), Engaged learning with emerging technologies, Springer, The Netherlands, 1-27 (2006)

27. MacKinnon, D.: The nature and nurture of creative talent, American Psychologist, 17, 484-495 (1962)

28. Karlins, M., Schuerhoff, C. and Kaplan, M.: Some factors related to architectural creativity in graduating architecture students, Journal of General Psychology, 81, 203-215 (1969)

22. Mednic, S.: The associative basis of the creative process, Psychological Review, 69, 220-232 (1962)

17. Moore, D.: Technology literacy: the extension of cognition, International Journal of Technology Design Education, 21,185-193 (2011)

6. Novak, M.: Next Babylon, Soft Babylon, in N. Spiller (ed.), Architects in Cyberspace II, Architectural Design, 68, 20-30 (1998)

20. Posngratz, C. and Perbellini, M.: Natural Born CAADesigners, Birkhauser, Switzerland, 5-30 (2000)

21. Rahim, A.: Contemporary processes in architecture, Architectural Design, 70, 6-11 (2000)

18. Rosenberger, R.: The sudden experience of the computer, AI and Society, 24, 173-180 (2009)

25. Runco, M. and Chand, I.: Cognition and Creativity, Educational Psychology Review, 7, 243-267 (1995)

13.Salomon, G., Perkins, D. and Globerson, T.: Partners in cognition: extending human intelligence with intelligent technologies, Educational Researcher, 20, 2-9 (1991)

2. Schweikardt, E. and Gross, M.: Digital clay: deriving digital models from freehand sketches, Automation in Construction, 9,107-115 (2000)

16. Spector, M. and Kinshuk: Learning to solve problems in the digital age: introduction, in D. Ifenthaler, P. Isaias, M. Spector, Kinshuk and D. Sampson (eds.), Multiple perspectives on problem solving and learning in the digital age, Springer Science + Business Media LLC, New York , 1-11 (2011) 
24. Torrance, P.: The Torrance tests of creative thinking norms; Technical Manual Research Edition-Verbal Tests, Forms A and B-Figural Tests, Forms A and B, Princeton, Personnel, NJ (1966) 